\title{
A Virtual Laboratory CD-ROM for Distance Students
}

\author{
Renay Buchanan \\ Central Queensland University, Australia
}

R.Buchanan@cqu.edu.au

\begin{abstract}
The main objective of the CD-ROM project is to provide all students, especially distance learners, with a virtual laboratory environment where they can be exposed to the physical and technical aspects of electronic communication equipment. We believe this CD-ROM resource will contribute towards the enhancement of the distance education experience and go some way to providing educational equity.
\end{abstract}

Keywords: Virtual, Laboratory, Distance, CD-ROM.

\section{Introduction}

The Central Queensland University (CQU), formerly the Capricorn College of Advanced Education (CIAE) has been delivering education to internal and distance students for around 25 years. Over that time there has been a constant struggle to try to achieve an engaging education experience that can be delivered to all students. In an attempt to transport the physical laboratory to the distance student we have created a multimedia CD-ROM that incorporates many of the live face-to-face learning experiences internal students receive when participating in the on-campus delivery of a subject.

\section{Discussion}

Currently the live interactive and visual experience has only been available to CQU's internal students at Rockhampton, and to a limited degree those students on the three regional campuses throughout Queensland who join the lecture via videoconference. The CD-ROM resource package aims to give distance students the opportunity to examine virtual pieces of hardware accompanied by audio and visual explanations that detail their physical and technical attributes.

Material published as part of this proceedings, either on-line or in print, is copyrighted by the author with permission granted to the publisher of Informing Science for this printing. Permission to make digital or paper copy of part or all of these works for personal or classroom use is granted without fee provided that the copies are not made or distributed for profit or commercial advantage AND that copies 1) bear this notice in full and 2) give the full citation on the first page. It is permissible to abstract these works so long as credit is given. To copy in all other cases or to republish or to post on a server or to redistribute to lists requires specific permission from the author.
Many of the concepts and techniques taught in Data Communications and Networks are of a practical nature, but in the past there has been no way of conveying the same message as the face-to-face, hands-on experience. After careful study of the syllabus we have been able to identify and incorporate critical knowledge items into a multimedia CD-ROM. This we believe will help to bridge the gap between the written word students are presented in their textbooks and the actual environment they will experience in the working world. The current student ratio for these subjects is $34 \%$ External and $66 \%$ Internal students, of which only $18 \%$ of the Internal students currently have access to all the interactive activities. With such a large percentage of students not being able to access important interactive activities it is essential that those activities be delivered via another medium.

The development of the CD-ROM presentation has been a team approach directed by the Faculty of Informatics and Communication. The invaluable contribution of practical and technical expertise from various divisions within the University, especially the Information Technology Division (ITD), has enabled us to incorporate in the multimedia package a virtual tour of the University corporate infrastructure networking facilities.

The CD-ROM experience consists of a menu based Multimedia presentation created using Macromedia Director 8. The presentation enables each student to view digital photographs, audio and video representing the sights and sounds that would normally be experienced in lectures, laboratories and tours. Packaging these features on a selfcontained CD-ROM enables us to effectively disseminate this, otherwise inaccessible experience, to all distance stu- 


\section{A Virtual Laboratory CD-ROM}

dents around the world without the need for them to access Internet technology that can be expensive and unreliable.

At the beginning of the multimedia presentation students are given two main menu options: Enter the Digital Photo Gallery, or Take a Virtual Tour of ITD. If the student chooses to view the Digital Photo Gallery they will select a category first, then one of the items from the list of hardware that might typically be found in these situations. The gallery provides digital photographs and a short written explanation of the technical and physical aspects of the device. From any point in the presentation navigation buttons allow the student to return to the list of hardware devices or the main menu screen.

If the student chooses to take The Virtual Tour of ITD they are introduced to the Tour menu with a short "sting", which is made up of a sequence of images taken from the tour and accompanied by music. There are six short videos to choose from lasting no more then three and a half minutes in duration. After choosing to view one of the videos an additional "director stage" is created and a QuickTime movie is played. On completion of the QuickTime movie the student is returned to the Tour menu and is able to select and view another short video or return to the main menu.

The main objective of this project is to provide all students, especially distance learners, with a virtual laboratory environment where they can be exposed to the physical and technical aspects of electronic communication equipment. We believe this CD-ROM resource will contribute to the enhancement of the distance education experience and go some way towards providing educational equity.

Many of the other virtual laboratories or classrooms that have been developed by other Australian or overseas Universities have been developed to be delivered via the Internet and sometimes include interactivity (Wilson \& Mosher, 1994), or simulations/animations (Buchanan \& Millard, 1999). The majority of topic areas that have been transformed into virtual laboratories have come from the areas of Science, Engineering or Mathematics. In these areas the ability to test theories or perform experiments is crucial to knowledge formation and assessment.

The reason for creating a virtual laboratory on CD-ROM was twofold. Firstly, we needed a resource that could be easily distributed to all students, regardless of geographical location or access to the Internet. And secondly, to produce a final product that did not require interactivity or outside information or stimulus.

Even though one of the main drawbacks of distance learning is the lack of interaction experienced (Rodriguez, et al, 1998). We contend that another major drawback for technology-based subjects is the exposure to the equipment and its place in the data communications environment. This is the gap we are trying to bridge with the Virtual Laboratory CD-ROM.

\section{Conclusion}

This CD-ROM is not meant to be an interactive virtual laboratory, nor a home study kit, nor a simulation of reality with predefined questions and answers, nor the static material presented in printed resource materials, textbooks or videotapes of lectures (Alhalabi, Hamza, Hsu \& Anandapuram 1999). It is meant to be a combination of all of these, presented in a way that allows all students to access the experience from their homes, independent of time and without the additional expense of, sometimes unreliable, Internet access. It must be stressed that this CD-ROM is designed to be an extra resource, and was not created to be an essential teaching or learning tool. Our aim is to transfer to all students some of the experience and real life visual stimulus available currently to only a small portion of the students studying this subject.

\section{References}

Alhalabi, Bassem; Hamza, M. Khalid; Hsu, Sam \& Anandapuram, Sudeep (1999). Virtual Education: Reality or Virtuality? In: SITE 99: Society for Information Technology \& Teacher Education International Conference (10th, San Antonio, TX, February 28March 4, 1999); see IR 019 584. (ERIC Database \# ED432293)

Buchanan, Renay \& Millard, Brendan (1999). Incorporating Animations in the theoretical teaching of Networks. In: 4th International conference on Computer Based Learning In Science (CBLIS) proceedings (4th, Enschede, The Netherlands, July 7-11, 1999).

Rodriguez, Blanca; Perez, Maria Angeles; Verdu, Maria Jesus; Navazo, Maria Agustina; Lopez, Ricardo; Mompo, Rafael \& Garcia, Joaquin (1998). Virtual Class: Distance Learning for Small and Medium Sized Enterprises in the Spanish Region of Castilla $y$ Leon. In: WebNet 98 World Conference of the WWW, Internet and Intranet Proceedings (3rd, Orlando, FL, November 7-12, 1998); see IR 019 231. (ERIC Database \# ED427731)

Wilson, Jack M. \& Mosher, David N. (1994). Interactive Multimedia Distance Learning (IMDL): The Prototype of the Virtual Classroom. In: Educational Multimedia and Hypermedia, 1994. Proceedings of ED-MEDIA 94 -World Conference on Educational Multimedia and Hypermedia (Vancouver, British Columbia, Can- 


\section{Renay Buchanan}

ada, June 25-30, 1994); see IR 017 359. (ERIC Database \#ED388303)

\section{Biographies}

Renay Buchanan is a Lecturer, in the Faculty of Informatics and Communication, at the Central Queesland
University, where she teaches Data Communications and Networking courses. Much of the research and development that Renay has contributed to over the past 10 years has been in the areas of Computer Aided Learning, Simulations and Professional and Distance Education. 